OPEN ACCESS

Edited by:

Fabrizio Schifano

University of Hertfordshire,

United Kingdom

Reviewed by:

Amira Guirguis,

Swansea University, United Kingdom

Georgios Demetrios Kotzalidis,

Sapienza University of Rome, Italy

${ }^{*}$ Correspondence:

Jody L. Green

jgreen@inflexxion.com

Specialty section:

This article was submitted to

Addictive Disorders,

a section of the journal

Frontiers in Psychiatry

Received: 20 November 2020

Accepted: 16 December 2020

Published: 25 January 2021

Citation:

Vosburg SK, Robbins RS, Antshel KM,

Faraone SV and Green JL (2021)

Characterizing Pathways of Non-oral Prescription Stimulant Non-medical

Use Among Adults Recruited From

Reddit. Front. Psychiatry 11:631792.

doi: 10.3389/fpsyt.2020.631792

\section{Characterizing Pathways of Non-oral Prescription Stimulant Non-medical Use Among Adults Recruited From Reddit}

\author{
Suzanne K. Vosburg ${ }^{1}$, Rebekkah S. Robbins ${ }^{1}$, Kevin M. Antshel ${ }^{2}$, Stephen V. Faraone ${ }^{3}$ and \\ Jody L. Green ${ }^{1 *}$
}

${ }^{1}$ Inflexxion, An IBH Company, Costa Mesa, CA, United States, ${ }^{2}$ Department of Psychology, Syracuse University, Syracuse, NY, United States, ${ }^{3}$ Department of Psychiatry, State University of New York (SUNY) Upstate Medical University, Syracuse, NY, United States

Objective: Prescription stimulant non-medical use (NMU) is a national predicament. While the risks of prescription stimulant NMU have been considered, less is known about non-oral use. To focus on this gap, a sample of adults with non-oral prescription stimulant NMU within the last 5-years was recruited. The purpose of the present study was to characterize the pathways and substance transitions associated with prescription stimulant NMU and non-oral prescription stimulant NMU in this unique sample of adults.

Methods: Adults $(n=225)$ reporting non-oral prescription stimulant NMU within the last 5 years were recruited to complete an online survey by banner ads placed on the Reddit website between February and September 2019. After completion of the survey, a second study consisting of an in-depth telephone interview was conducted with 23 participants: interviews took place between July and September 2019. Data reported here include substance, route of administration and class transitions, as well as qualitative data from the interviews.

Results: Approximately 1 in 5 began their substance use trajectory with prescription stimulants (19.1\%). Other than marijuana, most exposures to illicit substances occurred after both initial prescription stimulant NMU and initial non-oral prescription stimulant NMU. The most frequently reported route of administration transition was from oral use to snorting ( $n=158,70.2 \%$ ), however, other route of administration transitions included oral use to injection drug use $(n=14,6 \%)$. In-depth interviews elaborated upon these transitions and indicated that prescription stimulant NMU was consequential to substance use pathways.

Conclusions: Oral prescription stimulant NMU was a precursor to non-oral prescription stimulant NMU. Non-oral prescription stimulant NMU was a precursor to illicit substance use, suggesting that prescription stimulant NMU impacts substance use pathways and revealing opportunities for intervention.

Keywords: ADHD, prescription stimulants, prescription stimulant non-medical use, prescription stimulant non-oral use, transitions 


\section{INTRODUCTION}

Prescription stimulant non-medical use (NMU) is a persistent, national dilemma (1-4). Medications containing amphetamines (e.g., Adderall, Vyvanse) or methylphenidate (e.g., Ritalin, Concerta, Focalin) are considered the most widely prescribed stimulants in the United States $(5,6)$, and are regarded as the most efficacious drugs in the management of ADHD symptomatology (7). These medications lead to regional elevations in brain dopamine (8-10) rendering them as potential candidates for non-medical use (NMU) and diversion $(8,11-17)$.

Non-oral NMU of prescription stimulants-use that involves alternate routes of administration including intranasal or intravenous routes-has been reported in adolescents (1821 ), college students (22-25), and adults (26-28). While the physical and psychiatric risks as well as mortality associated with prescription stimulant NMU have been considered (29-34), less is known about non-oral prescription stimulant NMU, which can include adverse physical outcomes, such as toxicity or tissue damage (35-40), and adverse mental health outcomes, such as anxiety or depression (41) or even psychosis (33).

The transition from oral to non-oral NMU of prescription stimulants is not yet well-documented. However, there is an analogous framework to be found in the study of opioid use pathways and transitions (42-47). For example, an opioid class transition is the precursory use of prescription opioids before the use of heroin (48-51). This class transition has been related to age, availability/supply, drug quality, and surrounding environments (52-56). An opioid route of administration (ROA) transition (e.g., swallowing intact tablets then transitioning to crushing the tablet and snorting or injecting) is thought to occur when individuals develop tolerance to effects of a substance and desire stronger effects, more rapid onset of effects, or a more economical way of achieving them $(42,43,57)$. Initial route of administration can also affect subsequent ROA choices and overall pattern of drug use $(58,59)$.

Substance transitions are broadly captured by polysubstance use or substitutions, i.e., when one substance is not available, another is used $(54,55)$. In addition to switching from one substance or route of administration to another, where previously used substances or routes of administration are no longer used, a substance transition can also mean that new substances (and by extension routes of administration) are simply added to the current repertoire. Which is to say, substance use trajectories are not necessarily linear.

Prescription stimulant NMU class transitions would include prescription stimulant NMU leading to illicit stimulant use, such as cocaine or non-prescription methamphetamine. Prescription stimulant NMU route of administration transitions may include moving between oral and non-oral routes of administration $(26,60)$. Prescription stimulant substance transitions would involve moving on to other substances after prescription stimulant NMU, a trajectory that is possible among individuals with polysubstance use; a characteristic reported in individuals endorsing prescription stimulant NMU (61-66).

The purpose of this paper is to inform future hypothesis generation by identifying substance transitions, route of administration transitions and class transitions that were reported by a sample of adults who undertook prescription stimulant non-oral NMU within the last 5 years. This convenience sample was recruited from Reddit. The study employed a mixed-method design incorporating quantitative and qualitative data analyses.

\section{MATERIALS AND METHODS}

For purposes of this study, NMU included ANY of the following: (1) use for any reason, even once, without your own prescription, (2) use in ways other than prescribed (such as taking more than prescribed, more often than prescribed, or for any other reason or way than prescribed), and (3) use for the feeling or experience the medication caused (such as a feeling of being high, enhancement of other drugs, prevention or treatment of withdrawal symptoms, or other feelings).

\section{Procedure}

Advertisement banners appeared on Reddit (http://www.reddit. com) from February through September 2019 for purposes of study recruitment. Banner ads stated that adults (aged 18 years or older) who were English-speaking, had personal experience of non-oral prescription stimulant NMU within the last 5 years, able to give informed consent and were interested in taking an online survey could click on an embedded survey link. The link took them to an online web survey hosting site (YouGov) for survey completion.

Respondents were first asked to provide written, informed consent to participate. Survey completion took $\sim 10-15 \mathrm{~min}$; participation could be stopped at any time. Respondents who completed the online survey were compensated with a \$20 e-gift card upon completion. Compensation was managed by a third party to reduce privacy concerns.

After completion of the online survey, individuals were presented with the option to participate in a more in-depth, semistructured, follow-up telephone interview to further elucidate their experience with prescription stimulant medications. If respondents agreed to complete the follow-up interview, a designated time was confirmed for interviewers to call them.

Verbal informed consent was acquired at the beginning of each telephone interview; interviews were audio recorded with the participant's permission. Interviewers used an interview guide with open-ended questions that were designed to elicit in-depth responses about participants' substance use. Participants were compensated an additional $\$ 25$ for their participation, and again, compensation was managed by a third party. After the interviews were transcribed, audio recordings were deleted. This study was approved by the New England Institutional Review Board (NEIRB): 120180324 \#137173.0.

\section{Survey and Follow-Up Interview Description}

The online survey consisted of four sections: demographics, medical history, history of prescription medication NMU, and history of illicit substance use with 15 broad topic areas. To ensure reliable and accurate prescription medication 
identification, product images were displayed and participants were asked to indicate those they had used. To determine use characteristics, such as motivations for use, respondents were asked to select among pre-determined, categorical responses, however, "Other" with a write-in response area was always an option. Skip logic was employed so that number of survey items varied depending on number of prescription medications that were identified as having been used non-medically. Follow-up interviews were $\sim 1 \mathrm{~h}$ in duration. At the outset, after informed consent had been provided, participants were asked to confirm the use of prescription stimulants that had been described in their online survey. After confirmation that this information was, indeed, accurate, participants were asked a series of openended questions detailing their use, a series of questions about their patterns and pathways to substance use and a series of questions about their experiences regarding manipulation deterrent formulations. For purposes of this report, the patterns and pathways of substance use are of interest.

\section{Data Handling and Analyses}

Survey data were uploaded to and stored on a password protected Inflexxion server that was only accessible by authorized study personnel. The server resided in a climate-controlled, locked facility with nightly backups. Audio recordings were destroyed after a transcription was made from the recordings.

All analyses were carried out using SAS Enterprise Guide Version 7.1 (Cary, NC). Self-reported responses to quantitative survey questions were analyzed with descriptive frequency analyses or ordered categorically. Interviews from the follow-up interview were transcribed using an AI transcription platform. Interview results were categorically combined and summarized on an individual level.

\section{RESULTS}

Between February and September 2019, 225 participants were recruited from Reddit and completed the online survey. The sample was primarily male $(86.2 \%)$, not of Spanish, Latino or Hispanic origin or descent (92.4\%), White (78.2\%), and 25+ years of age $(52.0 \%)$, with some amount of college education $(81.3 \%)$. Most were single $(67.6 \%)$ and working full-time or parttime (60.4\%) with an annual family income between $\$ 30,000$ and $\$ 99,999$ (49.3\%). The majority reported at least one psychiatric diagnosis in their lifetime (55.1\%), most of which were depression (32.9\%), anxiety $(28.9 \%)$, or $\mathrm{ADHD}(27.6 \%)$. Participants were on average, $18.7( \pm 3.7)$ years of age when they first initiated prescription stimulant NMU.

Twenty-three participants from the original sample $(10.2 \%)$ were contacted and completed follow-up interviews, between July and September 2019. This subset of participants was primarily male $(n=20,87.0 \%)$ and 28.2 (range 19-36) years of age. Almost half had obtained prescription stimulants through a healthcare provider $(n=11,47.8 \%)$ and almost all had obtained prescription stimulants through diversion $(n=22,95.7 \%)$. Qualitative follow-up interview results are presented in the latter half of this paper.
Among the full sample, lifetime prescription stimulant NMU included amphetamine $(n=209,92.9 \%)$ or methylphenidate $(n=103,45.8 \%)$. Other reported lifetime prescription drug use (with or without prescriptions, for any reason) included opioids (44.4\%), sedatives (40.9\%), muscle relaxants $(24.4 \%)$, sleep aids (23.6\%), and/or diet aids/appetite suppressants (8.0\%). In addition to lifetime prescription stimulant NMU, participants reported prescription stimulant NMU within the past year $(n=$ $171,76.0 \%)$ and/or within the past month $(n=81,36.0 \%)$, while some reported their last use as being longer than a year ago $(n=$ $54,24.0 \%)$. Past year and past 30-days prescription drug use were also reported, although to a lesser degree.

\section{Substance Transitions, Stimulant Class Transitions}

Slightly more than 3 of 4 began their substance use pathway with marijuana ( $n=173,76.9 \%)$, while almost 1 in 5 began this pathway with prescription stimulants ( $n=43,19.1 \%)$. Figure 1 summarizes the mean age and 95\% Confidence Interval (95\% CI) at which various illicit substances were initially used by the sample in relation to prescription stimulants. Figure 1 reveals that marijuana use began earlier than other illicit drug use (95\% CIs do not cross with any other substance). Otherwise, the $95 \%$ CIs of the means overlap, revealing that the mean age of initiation did not substantially differ between prescription stimulant NMU and the use of remaining illicit substances, other than illicit fentanyl, that was initiated at a significantly later age than prescription stimulants.

\section{Stimulant Class Transitions}

Even though the differences were not statistically significant, chronologically, prescription stimulant NMU preceded illicit stimulant use (age of first prescription stimulant NMU: 18.7 \pm 3.7 years, age of first cocaine/crack use: $19.7 \pm 3.3$ years, age of first illicit amphetamine use: $20.1 \pm 4.6$ years). Three respondents $(1.3 \%)$ reported using only prescription stimulants non-medically without any illicit substance use.

Table 1 examines substance use patterns by mentions of initial exposure with substance and route of administration as one instance, hence more than one instance may be reported by one individual and frequencies may be greater than the sample size. For example, there were 259 mentions of marijuana use in this data set. Of these, $n=38(14.7 \%)$ mentions were the first oral use of marijuana and $n=221$ (85.3\%) were the first non-oral use of marijuana. Table 1, A columns summarizes how other than marijuana, most exposures to illicit substances occurred after the first episode of prescription stimulant NMU.

Specifically, $77.6 \%$ of marijuana exposures occurred prior to initiation of prescription stimulant NMU, while $22.4 \%$ occurred after the first prescription stimulant NMU. Further, $57.9 \%$ oral exposures were before and $42.1 \%$ exposures were after first prescription stimulant NMU, while $81.0 \%$ non-oral exposures were before and $19.0 \%$ non-oral exposures were after first prescription stimulant NMU. Representing a potential class transition, $77.9 \%$ cocaine exposures and $86.7 \%$ of illicit amphetamine or methamphetamine exposures occurred after prescription stimulant NMU. This pattern was also found for 


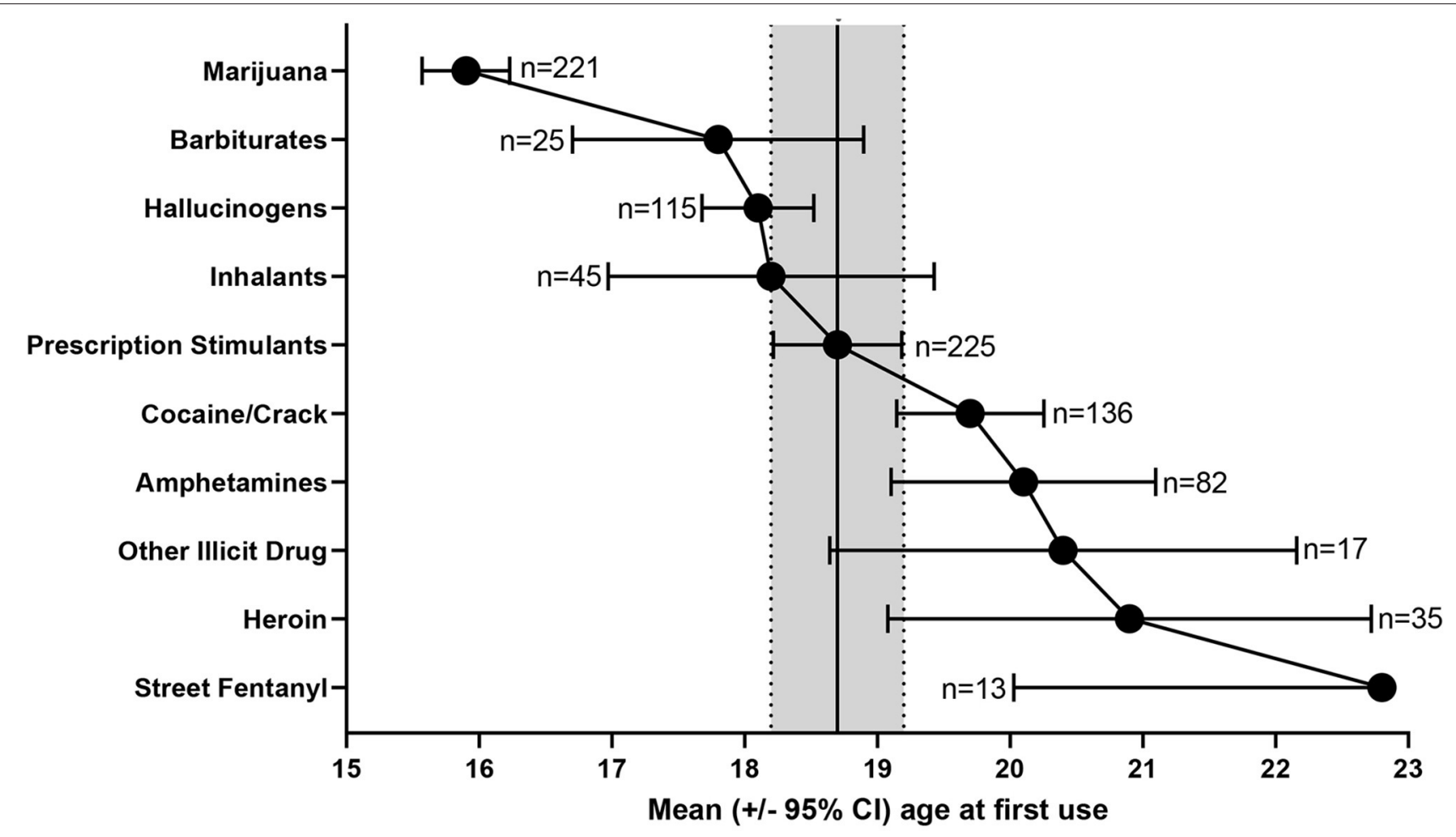

FIGURE 1 | Mean age $\pm 95 \% \mathrm{Cl}$ of initial prescription stimulant NMU and illicit substance use among individuals reporting non-oral prescription stimulant $\operatorname{NMU}(n=225)$.

other initial illicit substance exposures, for example, $62.0 \%$ of hallucinogen exposures, $89.7 \%$ heroin exposures, $82.1 \%$ of barbiturate exposures, etc., occurred after prescription stimulant NMU. This pattern held whether the illicit substance use was oral or non-oral (Table 1, A columns).

Table 1, B columns reveals that $80.9 \%$ of oral prescription stimulant NMU occurred prior to non-oral prescription stimulant NMU. In addition, most marijuana (85.3\%) and hallucinogen (57.7\%) exposures occurred prior to non-oral prescription stimulant NMU. Representing a potential class transition, cocaine exposures were almost evenly divided with slightly more exposures (51.4\%) occurring before initial non-oral prescription stimulant NMU, while most exposures to illicit amphetamines occurred after initial non-oral prescription stimulant NMU. Most exposures to the remainder of substances (heroin, barbiturates, inhalants, etc.) also occurred after initial non-oral prescription stimulant NMU; all exposures to fentanyl occurred after initial prescription stimulant non-oral NMU.

\section{Substance Transitions: Prescription Stimulant NMU to Prescription Opioid NMU}

In addition to prescription stimulant NMU and illicit drug use combinations, $\sim 38.2 \%$ of the sample ( $n=86,79.1 \%$ male, $20.9 \%$ female) reported lifetime prescription opioid NMU. Table 2 summarizes that a greater proportion of those with a history of prescription opioid NMU than without reported using prescription stimulants via any oral route (91.9 vs. $81.3 \%$ ) that included cutting and breaking their prescription stimulants into smaller pieces before swallowing ( 31.4 vs. $5.8 \%$ ), as well as chewing them before swallowing (20.9 vs. 5.8\%). Among non-oral routes of administration, a greater proportion of those with a history of prescription opioid NMU than without reported smoking ( 8.1 vs. $0.7 \%$ ) or injecting (10.5 vs. $3.6 \%$ ) prescription stimulants.

\section{Prescription Stimulant Route of Administration Transitions}

Figure 2 depicts transitions among the various routes of administration employed for prescription stimulant NMU among individuals who reported non-oral NMU experience. The first route of administration reported was either oral (swallowing: $n=173,76.9 \%$ ) or intranasal/snorting (snorting: $n=52$, $23.1 \%)$. Figure $2 \mathrm{~A}$ depicts that the majority, $70.2 \%(n=158)$, snorted after initial oral use, and did not transition beyond that experience. Other patterns along this pathway involved oral$>$ snort->inject $(n=7,3.1 \%)$, oral->snort-> smoke $(n=2$, $0.9 \%)$, or oral- $>$ snort- $>$ smoke- $>$ inject $(n=2,0.9 \%)$. Remaining pathways involved oral->smoke $(1 \%)$, oral- $>$ smoke- $>$ snort $(n$ $=1$ ), or oral- $>$ smoke- $>$ inject- $>$ snort $(n=1)$. One individual reported oral use and transitioning to prescription stimulant injection. 
TABLE 1 | Substance transitions: lifetime illicit substance use in relation to prescription stimulant NMU organized by whether initial substance exposure took place before or after the first episode of prescription stimulant NMU (A) or before or after the first episode of prescription stimulant non-oral NMU (B).

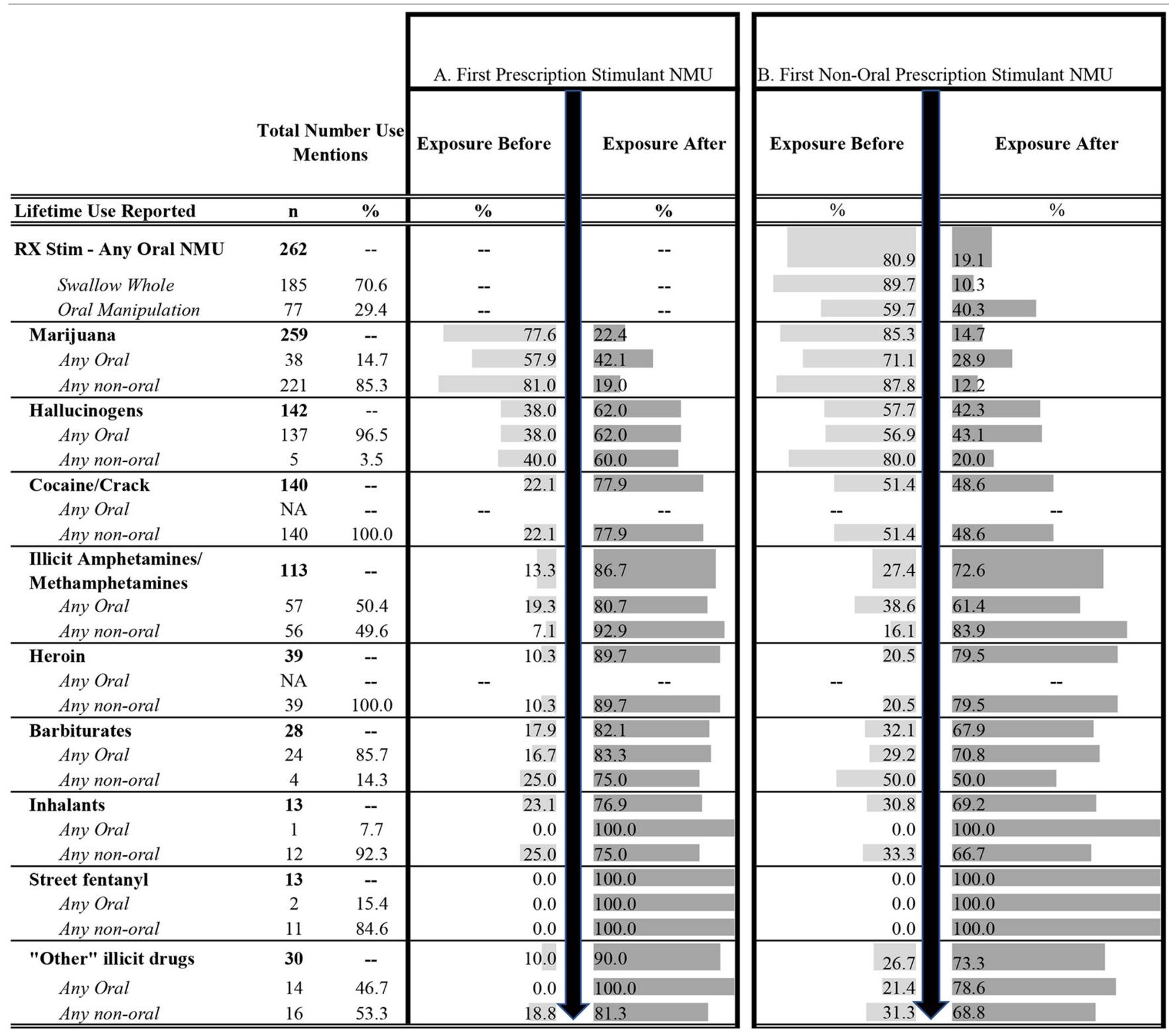

${ }^{a}$ Analysis includes all oral and non-oral routes of administration reported for substances ever used by respondents reporting lifetime non-oral NMU of prescription stimulants. 'Other' routes reported for substances listed are not included.

${ }^{b}$ Initiation before or after prescription stimulant NMU initiation was determined by the respondents self-reported order of first time a route route/substance combination was used. ${ }^{c}$ Any oral includes swallowing whole or chewing or dissolving before swallowing.

'Oral manipulation includes chewing or dissolving before swallowing.

${ }^{e}$ Any non-oral includes snorting, smoking, or injecting.

Figure 2B depicts that the remainder, 23.1\% $(n=52)$, snorted prescription stimulants for NMU first. Of those, $n=32(14.2 \%$ of the entire sample/61.5\% of those who snorted prescription stimulants for NMU first) did not transition to another route of administration. Other patterns involved snorting to oral use ( $n$ $=16,7.1 \%)$ snort- $>$ oral- $>$ inject $(n=2,0.9 \%)$, or snort- $>$ oral$>$ smoke $(n=1)$. One individual reported snorting and then transitioning to prescription stimulant injection.

\section{Follow-Up Interview Depicting Motivations and Transitions}

Table 3 summarizes motivations, positive and negative effects of prescription stimulant NMU endorsed by participants who completed the follow-up qualitative study $(n=23)$. Prescription Stimulant NMU was undertaken to enhance school work or work performance $(n=16,69.6 \%)$ for recreational substance use, such as to get high or party $(n=16,69.6 \%)$, or for the desire to treat 
TABLE 2 | Routes of administration for prescription stimulant NMU with or without lifetime prescription opioid NMU.

\begin{tabular}{|c|c|c|c|c|}
\hline \multirow[t]{2}{*}{ Characteristics of sample } & \multicolumn{2}{|c|}{$\begin{array}{l}\text { Prescription stimulant non-oral NMU with } \\
\text { prescription opioid NMU }(n=86)\end{array}$} & \multicolumn{2}{|c|}{$\begin{array}{l}\text { Prescription stimulant non-oral NMU without } \\
\text { prescription opioid NMU }(n=139)\end{array}$} \\
\hline & $n$ & $\%$ & $n$ & $\%$ \\
\hline Any oral route & 79 & 91.9 & 113 & 81.3 \\
\hline Swallowed whole & 74 & 86.1 & 111 & 79.9 \\
\hline Cut or broke into smaller pieces then swallowed & 27 & 31.4 & 8 & 5.8 \\
\hline Chewed in mouth then swallowed & 18 & 20.9 & 8 & 5.8 \\
\hline Dissolved in liquid then swallowed & 9 & 10.5 & 7 & 5.0 \\
\hline Any Non-oral route & 86 & 100.0 & 139 & 100.0 \\
\hline Snorted & 85 & 98.8 & 138 & 99.3 \\
\hline Smoked & 7 & 8.1 & 1 & 0.7 \\
\hline Injected & 9 & 10.5 & 5 & 3.6 \\
\hline
\end{tabular}

ADHD when the regular dose was not achieving the effect ( $n$ $=11,47.8 \%$ ). Main positive effects of prescription stimulants included feeling Alert $(n=18,78.3 \%)$, Stimulated $(n=8,34.8 \%)$, or happy ( $n=7,30.4 \%$ ), whereas main negative effects included feeling tired $(n=17,73.9 \%)$, having a decreased appetite $(n=13$, $56.5 \%)$, or feeling anxious $(n=9,39.1 \%)$.

Almost all respondents reported oral prescription stimulant NMU ( $n=22,95.7 \%)$, and most reported that their first episode of prescription stimulant NMU was oral $(n=20$, $87.3 \%)$. Similarly, almost all reported snorting prescription stimulants $(n=22,95.7 \%)$ but few indicated that their first episode of NMU involved snorting $(n=3,13.0 \%)$. Thirteen percent $(n=3)$ reported injecting prescription stimulants. Participants did not typically endorse snorting or smoking for performance enhancement purposes. The primary motivation for snorting or injecting was to achieve a faster impact of the drug (snorting, $n=21,95.4 \%$; injecting, $n=2,66.7 \%$ ). Additional motivations for snorting included curiosity/others were doing it $(n=12,54.5 \%)$, a friend was doing it $(n$ $=3,13.6 \%)$ or the person liked it and thought it was cool $(n=6,27.3 \%)$. Additional motivations for injecting were the ritual $(n=1)$ or curiosity $(n=1)$. Table 4 summarizes representative responses endorsing various motivations to use prescription stimulants via snorting or injecting routes of administration.

Eight participants $(34.8 \%)$ said that prescription stimulant NMU influenced their subsequent use of illicit drugs. While there were numerous examples of illicit substances (primarily marijuana) influencing other illicit substance use, thirteen respondents (56.5\%) indicated that use of illicit substances influenced their decision to try prescription stimulant NMU. Four participants (17.4\%) reported that their initial prescription stimulant NMU affected their use of other prescription stimulants. Table 5 summarizes representative statements of these influential relationships. Supplementary Tables present the actual pathways among various substances reported by participants. Slightly more than half $(13 / 23 ; 56.5 \%)$ reported using cocaine after using prescription stimulants, which is a transition within the stimulant class in addition to ongoing polydrug use.

\section{DISCUSSION AND CONCLUSION}

The purpose of this investigation was to characterize prescription stimulant NMU class, route of administration and substance transitions. A unique, convenience sample of adults who reported non-oral prescription stimulant NMU within the last 5 years were recruited from Reddit. Qualitative interviews among a subsample provided an opportunity to examine transitions in greater detail. This work reveals a gap not only in the academic literature, but also in general healthcare where prescription stimulant NMU may not be recognized (67).

\section{Illicit Substance Transitions}

Almost $77 \%$ of the sample initiated an illicit substance use trajectory with marijuana during the ages that typically correspond to sophmore and junior years in high school. National Monitoring the Future surveys have found between 60 and $80 \%$ of high school sophmores report that marijuana has been "fairly easy" or "very easy" to obtain since 1992 (68), thus, this finding is not particularly surprising. Recent SAMSHA data indicating that $34.8 \%$ of adults from ages $18-25$ years of age and $13.3 \%$ of adults 26 and older reported using marijuana in the past year further support this finding (2).

Almost $20 \%$ of the sample initiated their illicit substance use trajectory with prescription stimulant NMU. Three of those individuals only reported prescription stimulant NMU and did not transition to another illicit substance. The remainder primarily transitioned to marijuana. Marijuana remains a Schedule 1 substance and is illegal at the federal level, however, state-level laws vary with regard to use of medical marijuana, recreational use of marijuana and decriminalization, suggesting varying levels of ongoing access and use across the USA; its ubiquitousness is reflected in this sample.

While prescription stimulants were not always the first substance of the use trajectory, they were also not the last. Most illicit substance use occurred after the initial prescription stimulant NMU. Slightly more than one-third (34.8\%) of participants in the qualitative study claimed that prescription stimulant NMU influenced their subsequent use of 
А Oral NMU first, $n=173(76.9 \%)$

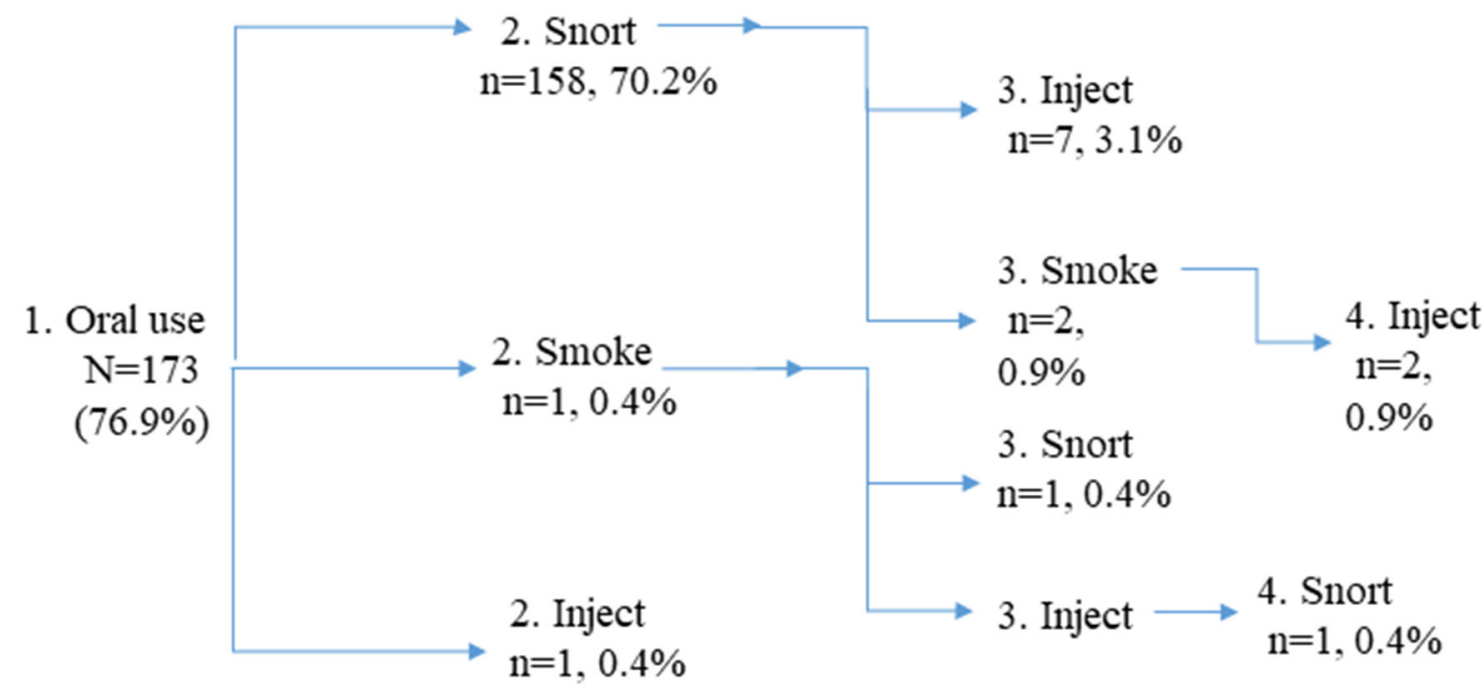

\section{в Intranasal/Snorting NMU first, $n=52$ (23.1\%)}

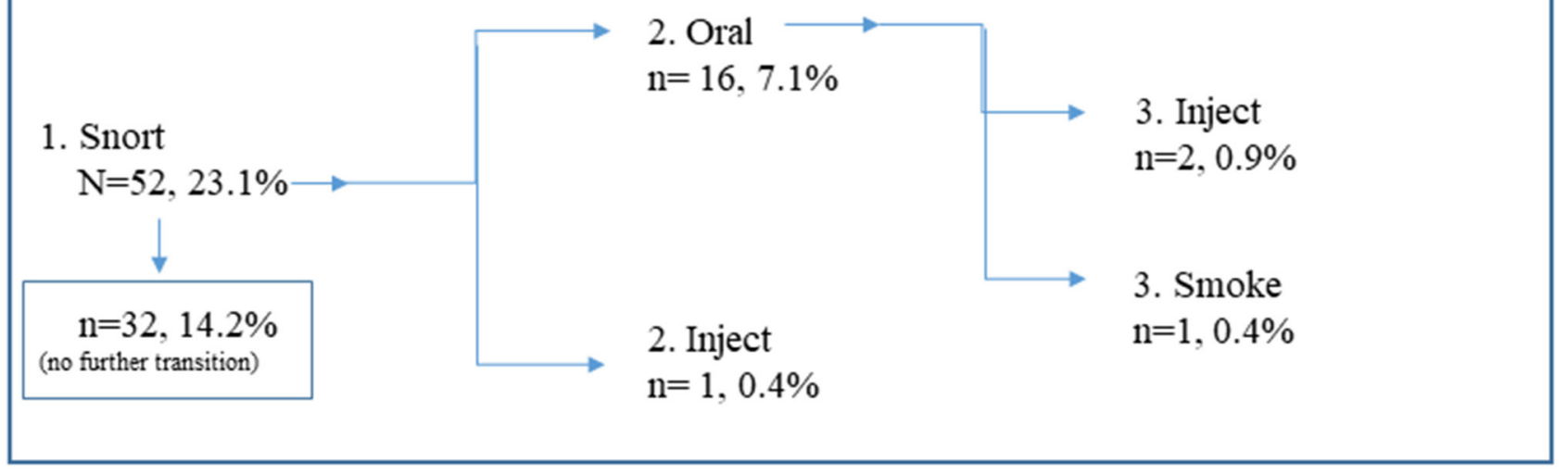

FIGURE 2 | Route of administration transitions for prescription stimulants. Note that linear depiction is only for purposes of illustration. Routes of administration vary as necessitated by access and situation. (A) Oral prescription stimulant use first ( $n=173,76.9 \%)$, (B) Intranasal prescription stimulant use first ( $n=52,23.1 \%)$.

illicit substances, while almost one-half endorsed prescription stimulant NMU when their regular dose was not achieving its effect, a noted risk factor for misuse (69). Recently, among multiple cohorts of high school seniors who were followed longitudinally, it was demonstrated that any reported prescription stimulant misuse (compared to none or rare misuse) was more strongly associated with subsequent substance use disorder symptoms at age 35 , including cannabis use disorder, other substance use disorder or any substance use disorder (70).

Prescription stimulants have also been found to be predictive factors in the development of illicit opioid use $(48,71)$ and increased concurrent use of opioids and stimulants has been represented in overdose deaths $(72,73)$, revealing a previously underappreciated level of risk associated with this particular trajectory. This finding is particularly important, given the recognition that many college-age students believe the level of risk associated with prescription stimulant NMU is low to nonexistent (74).

\section{Route of Administration Transitions}

Participants were recruited because they had used prescription stimulants non-orally, a risk factor for substance use severity $(57,66)$. For example, the speed of transition from first use to daily heroin was faster if the initial use was non-oral (injection) (58). Less is known and reported about the transitions from oral to non-oral prescription stimulant ROAs, other than they are likely to occur during the college years $(1,41,60)$, and that they are likely to occur (26-28). 
TABLE 3 | Motivations, positive and negative effects of prescription stimulant NMU among follow-up interview respondents ${ }^{*}$.

\begin{tabular}{|c|c|c|}
\hline Motivations & $n$ & $\%$ \\
\hline $\begin{array}{l}\text { To enhance school or work } \\
\text { performance }\end{array}$ & 16 & 69.6 \\
\hline Recreational use. To get high/party & 16 & 69.6 \\
\hline $\begin{array}{l}\text { To treat ADHD when regular dose } \\
\text { wasn't achieving effect }\end{array}$ & 11 & 47.8 \\
\hline For energy or to stay up & 10 & 43.5 \\
\hline To enhance effect of other drugs & 4 & 17.4 \\
\hline $\begin{array}{l}\text { To improve mood, self-medicate for } \\
\text { depression, anxiety }\end{array}$ & 3 & 13.0 \\
\hline $\begin{array}{l}\text { To prevent or treat withdrawal } \\
\text { symptoms }\end{array}$ & 1 & 4.3 \\
\hline \multicolumn{3}{|l|}{ Positive effects } \\
\hline $\begin{array}{l}\text { Alert, focused, awake, better } \\
\text { concentration }\end{array}$ & 18 & 78.3 \\
\hline High, good buzz, stimulated & 8 & 34.8 \\
\hline $\begin{array}{l}\text { Happy, elevated mood, less } \\
\text { depressed, less anxious) }\end{array}$ & 7 & 30.4 \\
\hline Calm & 6 & 26.1 \\
\hline Productive & 5 & 21.7 \\
\hline Social & 5 & 21.7 \\
\hline Energetic & 4 & 17.4 \\
\hline \multicolumn{3}{|l|}{ Negative effects } \\
\hline Insomnia, tired, exhausted & 17 & 73.9 \\
\hline Decreased appetite & 13 & 56.5 \\
\hline Anxiety & 9 & 39.1 \\
\hline Strung out, restless, antsy & 6 & 26.1 \\
\hline $\begin{array}{l}\text { Cold sweats, feel terrible after } \\
\text { crashing/coming down off stimulants }\end{array}$ & 5 & 21.7 \\
\hline Rapid heartrate/palpitations & 4 & 17.4 \\
\hline Paranoia and social anxiety & 4 & 17.4 \\
\hline Tense, achy, headaches & 3 & 13.0 \\
\hline Nausea & 3 & 13.0 \\
\hline Depression & 3 & 13.0 \\
\hline Irritable, impatient & 3 & 13.0 \\
\hline
\end{tabular}

${ }^{*}$ Responses are not mutually exclusive and do not sum to $100 \%$.

The present study found that the majority of the sample reported oral NMU prior to non-oral NMU. Most, after oral use, transitioned to snorting prescription stimulants $(\sim 70 \%)$, or only ever snorted prescription stimulants $(23 \%)$. These data add to recent findings that most non-oral use of prescription stimulants is intranasal among adults (26-28) and adolescents $(19,41)$.

However, among some, ROA moved beyond intranasal use to include smoking and injection. Intranasal and injection prescription stimulant NMU are associated with more severe medical outcomes than oral NMU (75), and thus awareness of these potential ROA transitions in prescription stimulant NMU is critical. For example, multiple, non-linear routes of administration have been reported for prescription opioid NMU (76) where approximately half of those interviewed transitioned to snorting or injection of prescription opioids before entering treatment. Similar to prescription stimulant ROA transitions, opioid ROA transitions were mostly to achieve a desired effect or due to social influences, where social influences typically led them to undertake a more dangerous ROA (76). Similar relationships may exist among prescrtipion stimulants, which is an avenue for future investigation.

\section{Class Transitions}

The present study found evidence of stimulant class transitions whereby (in addition to most illicit substance use), most illicit stimulant use occurred after prescription stimulant NMU. There is little to no available data on this specific transition. It has been found that early prescription drug NMU is associated with later prescription drug abuse and dependence (77), and prescription stimulant use is associated with subsequent substance use or dependence $(24,78)$. Similarly, the class transition from prescription to illicit substance has been noted with opioids where prescription opioids have pre-dated the use of heroin $(51,53,79)$. When the class transition was made to an illicit stimulant, cocaine, it was snorted, and in $12 / 2 / 3$ (52\%) of those interviewed, this occurred after previous prescription stimulants had been tampered with and/or snorted. Of $16.7 \%$ of those with lifetime cocaine use and $11.2 \%$ of those with lifetime amphetamine use go on to develop stimulant use disorders (80), and it is possible that the present data capture the initial stages of those trajectories.

\section{Limitations}

Data were obtained from a convenience sample of adults who were recruited from Reddit. Although Reddit is advertised as the 5th most visited website in the United States, this may not be a representative sample of adults who undertake non-oral prescription stimulant NMU. Reddit users have been characterized as young, male, regular internet users (81). Subsequent studies targeting non-oral prescription stimulant NMU are needed; the present study can inform hypothesis generation. Increasing attention is being paid to the use of Reddit specifically (82-87) for the conduct of substance use research. One distinct advantage of social media platforms is the potential reach to hidden populations, such as substance users (88). Although data are selfreported, given the nature of the information disclosed, it is possible that anonymous online surveys may increase the likelihood of truthful reporting. In the present study, the self-reported information collected in the quantitative survey was verified and detailed among those who participated in the follow-up interviews.

Temporal relationships alone cannot determine causality. While a mixed methods approach was used to capture motivation and factors that influenced trajectories of substance use, we are unable to quantify the causal relationship between prescription stimulant NMU (or non-oral prescription stimulant NMU) and subsequent drug use patterns. Quantitative data measure study outcomes with precise, numerical data that can be generalized and compared with statistical tests that are widely recognized (89). However, such data can also be overly general and, as a result, decontextualize the environment 
TABLE 4 | Motivations for snorting or injecting prescription stimulants for $\operatorname{NMU}(n=23)$.

\section{INTRANASAL}

\section{Faster impact}

- I knew the effect would take on faster and it was just curiosity I suppose. When I was experimenting with that I would swallow one pill whole and then while that was I guess digesting I would crush and snort a different pill

- The immediate effect was definitely the reason. The effects overall were shorter lasting but more powerful in that method of use. I think so that was probably the main reason the immediacy of the effect of the drug

- About 10-20 min faster than swallowing. I mean the oral takes about 10-20 min more than snorting it. Yes. And you when you snort it it's about 5, 5-10 min

- Oh, absolutely I mean you know it hit you in the face like a truck and you feel like the most productive worker in the world. You can get up and you can conquer anything you want it makes you feel empowered if that makes sense

\section{Curiosity/Others were doing it/A friend was doing it}

- I was kind of introduced to it for the most part. And like you get that drip on the back of your throat when you do it. The constant reminder kind of higher by the availability and a lot of other methods for quick acting methods and so the constant taste is kind of a reminder, I guess

- So, generally with friends it's a little more of a party thing. You know they all wanted to snort it, and nobody wanted to eat it just because it's cool to snort drugs or whatever. And so that's usually how it would go down. When I was in the company of others

- I was dating a girl that had it and was doing it and I decided to try it

\section{Liked it and thought it was cool}

- It was cool to snort

- Pretty much snorting. I mean I did other stuff like coke and stuff like that way before. So, I was kind of already in that mindset

\section{INTRAVENOUS}

\section{Faster impact (Intravenous)}

- I mean I told you earlier snorting it take maybe a few minutes and then you go on and you feel kind of good. But when you inject, it immediately hits. I mean as soon as you plunge the plunger down it immediately hits, and you get hit stronger and harder than any other way would hit

\section{Ritual}

- ... As my addiction progressed, I wouldn't do anything if I couldn't shoot it. Basically

- And through it all I feel like I was just as addicted to the using and the like the ritual of preparing the injection and all that just as much. You know it was just part of it

\section{Curiosity (Intravenous)}

- That was in part sheer dumb curiosity and reports I've read from the Internet. A lot of people on the Internet dangerously overhype what that's like. And you know it's very tempting once you're that far in: where you're already snorting and you're already taking it every day to say, well ... how much more harmful than the next step be. And it is that much harmful because it is it's you know I don't want to say great but it's really great when you do that. ....(sic)

TABLE 5 | Examples of influences associated with prescription stimulant NMU among interview respondents $(n=23)$.

\section{Influence of prescription stimulant NMU on illicit substance use}

- Oh of course it did. Because it has opened up a world to me of not feeling pain. So, of course I was open to the idea of trying to have the feeling that this thing worked so well that I might as well see what else is out there

- Experience with methylphenidate product influenced me to try other 'speedy sort of drugs', in particular cocaine

- Methylphenidate product was a substitute for cocaine high

- Amphetamine product helped with studying and cramming purposes, partying, enhancing marijuana and alcohol intake, could drink more and party longer

\section{Influence of illicit substances on prescription stimulant NMU}

- When (I) couldn't get cocaine (I) would inject prescription stimulants to try and chase that "cocaine high"

- The biggest influence for me to start snorting ....was my marijuana use was extreme. I was using the amphetamine product to enhance that and get a little bit higher from it. And this all probably played into it as well. But I was having severe depression symptoms and I was kind that was a coping mechanism although temporary

\section{Influence of prescription stimulant NMU on other prescription stimulant NMU}

- Positive experience with amphetamine products led me to be curious/try other prescription stimulants/fun habit/Positive experience with long-acting amphetamine products led me to try other time release stimulants

- Curious to see how it (methylphenidate product) felt compared to amphetamine product

- Wanted to find something to avoid sundowning/effect of amphetamine product wearing off

- Crushed them and snorted or crushed them and ate them.... because I was cramming for a test. Extra schoolwork

- I was looking for an effect similar to amphetamine product and I was looking for sort of a potent something to keep me awake. It's something to keep me focused while I was doing work and that's why I snorted it instead of swallowing it which I felt like would be a less potent dose

- Experience with amphetamine product influenced the use of other prescription stimulants as a result of amphetamine product getting too expensive for regular use

- Amphetamine product made more comfortable taking prescription stimulants. So, if preference wasn't available, felt pretty comfortable going to another prescription stimulant

- Well yes I did. I suppose if anything it made me more want to acquire amphetamine product to keep with that and have a more consistent supply because I saw the value of it both for academically and for partying 
in which the outcomes of interest (in this case, substance use behaviors) take place (90). They may not convey the "lived experience" (91). Qualitative data, where the word is the unit of analysis, are employed to examine experiences or processes and can convey meaning and subtlety in a way that numbers alone cannot (90). The mixed method strategy, including quantitative and qualitative data collected together (92) allows for a more nuanced interpretation of each type of data (93) and as such, is a design choice that is particularly useful in the study of non-medical substance use behaviors (74). These behaviors are not only difficult to quantify, but are stigmatized and often difficult to find and detail in the general population, rendering mixed methodology a useful and valuable data collection strategy. In the present study, this strategy enabled a rich characterization of transitions and use pathways.

\section{Conclusion and Future Directions}

This study found prescription stimulant NMU to be associated with substance transitions, route of administration transitions and class transitions, which is a novel clarification of the risks associated with this type of substance use. This study was undertaken before the FDA issued the Register notice [FDA2019-N-3403; Federal Register 84 (183), September 20, 2019], however, some of the findings may inform the questions raised in that document, specifically, whether there may be a role for manipulation resistant formulations in the current misuse and abuse of prescription stimulants. While illicit stimulants are not data presented herein may be used to inform future studies that address whether interventions, such as manipulation resistance formulations of prescription stimulant medications, may disrupt the key transitions that are part of substance use trajectories.

\section{REFERENCES}

1. Cottler LB, Striley CW, Lasopa SO. Assessing prescription stimulant use, misuse, and diversion among youth 10-18 years of age. Curr Opin Psychiatry. (2013) 26:511-9. doi: 10.1097/YCO.0b013e32836 $42 \mathrm{cb} 6$

2. SAMSHA. Key Substance Use and Mental Health Indicators in the United States: Results From the 2018 National Survey on Drug Use and Health (HHS Publication No. PEP19-5068 NSDUH NSDUH Series H-54). Rockville, MD: SAMSHA (2019).

3. Teter CJ, McCabe SE, Boyd CJ, Guthrie SK. Illicit methylphenidate use in an undergraduate student sample: prevalence and risk factors. Pharmacotherapy. (2003) 23:609-17. doi: 10.1592/phco.23.5.609.34187

4. U.S. Drug Enforcement Administration. National Forensic Laboratory Information System: NFLIS-Drug 2019 Midyear Report. Springfield, VA: US Drug Enforcement Administration (2020).

5. DEA. National Forensic Laboratory Information System Special Report: ADD/ADHD Stimulants in NFLIS, 2007-2011. Springfield, VA: DEA (2012).

6. Piper BJ, Ogden CL, Simoyan OM, Chung DY, Caggiano JF, Nichols $\mathrm{SD}$, et al. Trends in use of prescription stimulants in the United States and territories, 2006 to 2016. PLoS ONE. (2018) 13:e0206100. doi: 10.1371/journal.pone.0206100

7. Kaye S, Darke S. The diversion and misuse of pharmaceutical stimulants: what do we know and why should we care? Addiction. (2012) 107:467-77. doi: 10.1111/j.1360-0443.2011.03720.x

\section{DATA AVAILABILITY STATEMENT}

Data are proprietary. Requests to access the data may be considered.

\section{ETHICS STATEMENT}

The studies involving human participants were reviewed and approved by New England Institutional Review Board. The patients/participants provided their written informed consent to participate in this study.

\section{AUTHOR CONTRIBUTIONS}

SV evaluated early data analyses, suggested subsequent data analyses, wrote the first draft, and revised the manuscript. RR suggested and conducted data analyses and reviewed the manuscript. KA and SF reviewed the manuscript and made significant helpful suggestions and comments. JG acquired funding, designed and oversaw the study, suggested data analyses, and reviewed and commented on the manuscript extensively. All authors contributed to the article and approved the submitted version.

\section{FUNDING}

Funding for this research was provided by Arbor Pharmaceuticals, LLC.

\section{SUPPLEMENTARY MATERIAL}

The Supplementary Material for this article can be found online at: https:/www.frontiersin.org/articles/10.3389/fpsyt. 2020.631792/full\#supplementary-material

8. Clemow DB. Misuse of methylphenidate. Curr Top Behav Neurosci. (2017) 34:99-124. doi: 10.1007/7854_2015_426

9. Clemow DB, Walker DJ. The potential for misuse and abuse of medications in ADHD: a review. Postgrad Med. (2014) 126:64-81. doi: 10.3810/pgm.2014.09.2801

10. Faraone SV. The pharmacology of amphetamine and methylphenidate: relevance to the neurobiology of attention-deficit/hyperactivity disorder and other psychiatric comorbidities. Neurosci Biobehav Rev. (2018) 87:255-70. doi: 10.1016/j.neubiorev.2018.02.001

11. Holt LJ, McCarthy MD. Predictors of prescription stimulant misuse in U.S. College graduates. Subst Use Misuse. (2020) 55:644-57. doi: 10.1080/10826084.2019.1692867

12. Lasopa SO, Striley CW, Cottler LB. Diversion of prescription stimulant drugs among 10-18-year-olds. Curr Opin Psychiatry. (2015) 28:292-8. doi: 10.1097/YCO.0000000000000172

13. McCabe SE, Teter CJ, Boyd CJ. Medical use, illicit use, and diversion of abusable prescription drugs. J Am Coll Health. (2006) 54:269-78. doi: 10.3200/JACH.54.5.269-278

14. McCabe SE, Teter CJ, Boyd CJ. Medical use, illicit use and diversion of prescription stimulant medication. J Psychoactive Drugs. (2006) 38:43-56. doi: 10.1080/02791072.2006.10399827

15. Weyandt LL, Oster DR, Marraccini ME, Gudmundsdottir BG, Munro BA, Rathkey ES, et al. Prescription stimulant medication misuse: where are we and where do we go from here? Exp Clin Psychopharmacol. (2016) 24:400-14. doi: $10.1037 /$ pha0000093 
16. Wilens TE, Adler LA, Adams J, Sgambati S, Rotrosen J, Sawtelle R, et al. Misuse and diversion of stimulants prescribed for ADHD: a systematic review of the literature. J Am Acad Child Adolesc Psychiatry. (2008) 47:21-31. doi: 10.1097/chi.0b013e31815a56f1

17. Wilens TE, Isenberg BM, Kaminski TA, Lyons RM, Quintero J. Attentiondeficit/hyperactivity disorder and transitional aged youth. Curr Psychiatry Rep. (2018) 20:100. doi: 10.1007/s11920-018-0968-x

18. McCabe SE, West BT, Schepis TS, Teter CJ. Simultaneous co-ingestion of prescription stimulants, alcohol and other drugs: a multi-cohort national study of US adolescents. Hum Psychopharmacol. (2015) 30:42-51. doi: 10.1002/hup.2449

19. Vosburg SK, Faraone SV, Newcorn JH, Rostain AL, Findling RL, Butler SF, et al. Prescription stimulant nonmedical use among adolescents evaluated for substance use disorder treatment $\left(\mathrm{CHAT}^{\mathrm{TM}}\right)$. J Affect Disord. (2020). doi: $10.1177 / 1087054720943283$

20. Wilens TE, Gignac M, Swezey A, Monuteaux MC, Biederman J. Characteristics of adolescents and young adults with ADHD who divert or misuse their prescribed medications. J Am Acad Child Adolesc Psychiatry. (2006) 45:408-14. doi: 10.1097/01.chi.0000199027.68828.b3

21. Zosel A, Bartelson BB, Bailey E, Lowenstein S, Dart R. Characterization of adolescent prescription drug abuse and misuse using the researched abuse diversion and addiction-related surveillance (RADARS $((\mathrm{R}))$ ) system. J Am Acad Child Adolesc Psychiatry. (2013) 52:196-204 e192. doi: 10.1016/j.jaac.2012.11.014

22. Barrett SP, Darredeau C, Bordy LE, Pihl RO. Characteristics of methylphenidate misuse in a university student sample. Can J Psychiatry. (2005) 50:457-61. doi: 10.1177/070674370505000805

23. DeSantis AD, Noar SM, Webb EM. Speeding through the frat house: a qualitative exploration of nonmedical ADHD stimulant use in fraternities. $J$ Drug Educ. (2010) 40:157-71. doi: 10.2190/DE.40.2.d

24. McCabe SE, Teter CJ. Drug use related problems among nonmedical users of prescription stimulants: a web-based survey of college students from a Midwestern university. Drug Alcohol Depend. (2007) 91:69-76. doi: 10.1016/j.drugalcdep.2007.05.010

25. Teter CJ, McCabe SE, LaGrange K, Cranford JA, Boyd CJ. Illicit use of specific prescription stimulants among college students: prevalence, motives, and routes of administration. Pharmacotherapy. (2006) 26:1501-10. doi: 10.1592/phco.26.10.1501

26. Burtner J, Behling M, Cassidy T, Butler SF. Prevalence of nonmedical use and routes of administration for prescription stimulant medications among adults in a substance abuse treatment population. J Addict Dis. (2018) 37:34-45. doi: 10.1080/10550887.2018.1512825

27. Cassidy TA, McNaughton EC, Varughese S, Russo L, Zulueta M, Butler SF. Nonmedical use of prescription ADHD stimulant medications among adults in a substance abuse treatment population: early findings from the NAVIPPRO surveillance system. J Atten Disord. (2015) 19:275-83. doi: $10.1177 / 1087054713493321$

28. Cassidy TA, Varughese S, Russo L, Budman SH, Eaton TA, Butler SF. Nonmedical use and diversion of ADHD stimulants among U.S. adults ages 18-49: a national internet survey. J Atten Disord. (2015) 19:630-40. doi: $10.1177 / 1087054712468486$

29. Barkus E, Murray RM. Substance use in adolescence and psychosis: clarifying the relationship. Annu Rev Clin Psychol. (2010) 6:365-89. doi: 10.1146/annurev.clinpsy.121208.131220

30. Cooper J, Jarrett M, Forrester A, di Forti M, Murray RM, Huddy V, et al. Substance use and at-risk mental state for psychosis in 2102 prisoners: the case for early detection and early intervention in prison. Early Interv Psychiatry. (2018) 12:400-9. doi: 10.1111/eip.12343

31. Hennissen L, Bakker MJ, Banaschewski T, Carucci S, Coghill D, Danckaerts $\mathrm{M}$, et al. Cardiovascular effects of stimulant and non-stimulant medication for children and adolescents with ADHD: a systematic review and meta-analysis of trials of methylphenidate, amphetamines and atomoxetine. CNS Drugs. (2017) 31:199-215. doi: 10.1007/s40263-017-0410-7

32. Westover AN, Nakonezny PA. Aortic dissection in young adults who abuse amphetamines. Am Heart J. (2010) 160:315-21. doi: 10.1016/j.ahj.2010.05.021

33. Westover AN, Nakonezny PA, Haley RW. Acute myocardial infarction in young adults who abuse amphetamines. Drug Alcohol Depend. (2008) 96:4956. doi: 10.1016/j.drugalcdep.2008.01.027
34. Westover AN, Nakonezny PA, Halm EA, Adinoff B. Risk of amphetamine use disorder and mortality among incident users of prescribed stimulant medications in the veterans administration. Addiction. (2018) 113:857-67. doi: 10.1111/add.14122

35. Bruggisser M, Bodmer M, Liechti ME. Severe toxicity due to injected but not oral or nasal abuse of methylphenidate tablets. Swiss Med Wkly. (2011) 141:w13267. doi: 10.4414/smw.2011.13267

36. Imbert B, Cohen J, Simon N. Intravenous abuse of methylphenidate. J Clin Psychopharmacol. (2013) 33:720-1. doi: 10.1097/JCP.0b013e31829839a4

37. Lile JA, Babalonis S, Emurian C, Martin CA, Wermeling DP, Kelly TH. Comparison of the behavioral and cardiovascular effects of intranasal and oral d-amphetamine in healthy human subjects. J Clin Pharmacol. (2011) 51:888-98. doi: 10.1177/0091270010375956

38. Marti G, Fattinger K, Zimmermann H, Exadaktylos A. Orofacial dyskinesia induced by nasal Ritalin(R) (methylphenidate) sniffing: a rare case report from Switzerland. Hum Exp Toxicol. (2013) 32:332-4. doi: 10.1177/0960327112467044

39. Massello WIII, Carpenter DA. A fatality due to the intranasal abuse of methylphenidate (Ritalin). J Forensic Sci. (1999) 44:220-1. doi: 10.1520/JFS14440J

40. Parran TVJr, Jasinski DR. Intravenous methylphenidate abuse. Prototype for prescription drug abuse. Arch Intern Med. (1991) 151:781-3. doi: 10.1001/archinte.1991.00400040119027

41. Liu Y, Smith NDL, Lloyd SL, Striley CW, Cottler LB. Prescription stimulant use and associated risk factors for non-oral use among 10 to 18 year olds. Psychoactive Drugs. (2020) 52:421-32. doi: 10.1080/02791072.2020.1795326

42. Cepeda JA, Astemborski J, Kirk GD, Celentano DD, Thomas DL, Mehta $\mathrm{SH}$. Rising role of prescription drugs as a portal to injection drug use and associated mortality in Baltimore, Maryland. PLoS ONE. (2019) 14:e0213357. doi: 10.1371/journal.pone.0213357

43. Des Jarlais DC, McKnight C, Arasteh K, Feelemyer J, Perlman DC, Hagan $\mathrm{H}$, et al. Transitions from injecting to non-injecting drug use: potential protection against HCV infection. J Subst Abuse Treat. (2014) 46:325-31. doi: 10.1016/j.jsat.2013.09.004

44. Gossop M, Stewart D, Marsden J, Kidd T, Strang J. Changes in route of drug administration among continuing heroin users: outcomes 1 year after intake to treatment. Addict Behav. (2004) 29:1085-94. doi: 10.1016/j.addbeh.2004.03.012

45. Strang J. Drug transitions: uncoupling drug and route. Addiction. (1999) 94:1787-8. doi: 10.1080/09652149932262

46. Strang J, Bearn J, Farrell M, Finch E, Gossop M, Griffiths P, et al. Route of drug use and its implications for drug effect, risk of dependence and health consequences. Drug Alcohol Rev. (1998) 17:197-211. doi: 10.1080/09595239800187001

47. Strang J, Des Jarlais DC, Griffiths P, Gossop M. The study of transitions in the route of drug use: the route from one route to another. Br J Addict. (1992) 87:473-83. doi: 10.1111/j.1360-0443.1992.tb 01948.x

48. Carlson RG, Nahhas RW, Martins SS, Daniulaityte R. Predictors of transition to heroin use among initially non-opioid dependent illicit pharmaceutical opioid users: a natural history study. Drug Alcohol Depend. (2016) 160:127-34. doi: 10.1016/j.drugalcdep.2015. 12.026

49. Catalano RF, White HR, Fleming CB, Haggerty KP. Is nonmedical prescription opiate use a unique form of illicit drug use? Addict Behav. (2011) 36:79-86. doi: 10.1016/j.addbeh.2010.08.028

50. Grau LE, Dasgupta N, Harvey AP, Irwin K, Givens A, Kinzly ML, et al. Illicit use of opioids: is OxyContin a "gateway drug"? Am J Addict. (2007) 16:166-73. doi: 10.1080/10550490701375293

51. Guarino H, Mateu-Gelabert P, Teubl J, Goodbody E. Young adults' opioid use trajectories: from nonmedical prescription opioid use to heroin, drug injection, drug treatment and overdose. Addict Behav. (2018) 86:118-23. doi: 10.1016/j.addbeh.2018.04.017

52. Cicero TJ, Ellis MS, Surratt HL. Effect of abuse-deterrent formulation of OxyContin. N Engl J Med. (2012) 367:187-9. doi: 10.1056/NEJMc1204141

53. Compton WM, Jones CM, Baldwin GT. Relationship between nonmedical prescription-opioid use and heroin use. N Engl J Med. (2016) 374:154-63. doi: 10.1056/NEJMra1508490 
54. Lankenau SE, Teti M, Silva K, Bloom JJ, Harocopos A, Treese M. Patterns of prescription drug misuse among young injection drug users. J Urban Health. (2012) 89:1004-16. doi: 10.1007/s11524-012-9691-9

55. Lankenau SE, Teti M, Silva K, Jackson Bloom J, Harocopos A, Treese M. Initiation into prescription opioid misuse amongst young injection drug users. Int J Drug Policy. (2012) 23:37-44. doi: 10.1016/j.drugpo.2011.05.014

56. Mars SG, Bourgois P, Karandinos G, Montero F, Ciccarone D. "Every 'never' I ever said came true": transitions from opioid pills to heroin injecting. Int $J$ Drug Policy. (2014) 25:257-66. doi: 10.1016/j.drugpo.2013.10.004

57. Katz N, Dart RC, Bailey E, Trudeau J, Osgood E, Paillard F. Tampering with prescription opioids: nature and extent of the problem, health consequences, and solutions. Am J Drug Alcohol Abuse. (2011) 37:205-17. doi: 10.3109/00952990.2011.569623

58. Hines LA, Lynskey M, Morley KI, Griffiths P, Gossop M, Powis B, et al. The relationship between initial route of heroin administration and speed of transition to daily heroin use. Drug Alcohol Rev. (2017) 36:633-8. doi: $10.1111 /$ dar. 12560

59. Neaigus A, Gyarmathy VA, Miller M, Frajzyngier VM, Friedman SR, Des Jarlais DC. Transitions to injecting drug use among noninjecting heroin users: social network influence and individual susceptibility. J Acquir Immune Defic Syndr. (2006) 41:493-503. doi: 10.1097/01.qai.0000186391.49205.3b

60. Weyandt LL, Marraccini ME, Gudmundsdottir BG, Zavras BM, Turcotte KD, Munro BA, et al. Misuse of prescription stimulants among college students: a review of the literature and implications for morphological and cognitive effects on brain functioning. Exp Clin Psychopharmacol. (2013) 21:385-407. doi: $10.1037 / \mathrm{a} 0034013$

61. Faraone SV, Rostain AL, Montano CB, Mason O, Antshel KM, Newcorn JH. Systematic review: nonmedical use of prescription stimulants: risk factors, outcomes, and risk reduction strategies. J Am Acad Child Adolesc Psychiatry. (2020) 59:100-12. doi: 10.1016/j.jaac.2019.06.012

62. McCabe SE, Veliz P, Wilens TE, Schulenberg JE. Adolescents' prescription stimulant use and adult functional outcomes: a national prospective study. J Am Acad Child Adolesc Psychiatry. (2017) 56:226-33 e224. doi: 10.1016/j.jaac.2016.12.008

63. Rabiner DL, Anastopoulos AD, Costello EJ, Hoyle RH, McCabe SE, Swartzwelder HS. The misuse and diversion of prescribed ADHD medications by college students. J Atten Disord. (2009) 13:144-53. doi: $10.1177 / 1087054708320414$

64. Teter CJ, McCabe SE, Cranford JA, Boyd CJ, Guthrie SK. Prevalence and motives for illicit use of prescription stimulants in an undergraduate student sample. J Am Coll Health. (2005) 53:253-62. doi: 10.3200/JACH.53.6.253-262

65. Wilens TE. The nature of the relationship between attentiondeficit/hyperactivity disorder and substance use. $J$ Clin Psychiatry. (2007) 68:4-8.

66. Wilens TE, Martelon M, Yule A, Kaminski TA, Burke C, Schepis TS, et al. Disentangling the social context of nonmedical use of prescription stimulants in college students. Am J Addict. (2020) 29:476-84. doi: 10.1111/ajad.13053

67. Pasha AK, Chowdhury A, Sadiq S, Fairbanks J, Sinha S. Substance use disorders: diagnosis and management for hospitalists. J Community Hosp Intern Med Perspect. (2020) 10:117-26. doi: 10.1080/20009666.2020.1742495

68. Johnston LD, Miech RA, O'Malley PM, Bachman JG, Schulenberg JE, Patrick ME. Monitoring the Future National Survey Results on Drug Use, 1975-2018: Overview, Key Findings on Adolescent Drug Use. Ann Arbor, MI: Institute for Social Research: The University of Michigan (2019).

69. Wilens TE, Kaminski TA. Prescription stimulants: from cognitive enhancement to misuse. Pediatr Clin North Am. (2019) 66:1109-20. doi: 10.1016/j.pcl.2019.08.006

70. McCabe SE, Veliz PT, Dickinson K, Schepis TS, Schulenberg JE. Trajectories of prescription drug misuse during the transition from late adolescence into adulthood in the USA: a national longitudinal multicohort study. Lancet Psychiatry. (2019) 6:840-50. doi: 10.1016/S2215-0366(19)30299-8

71. Daniulaityte R, Falck RS, Wang J, Carlson RG. Illicit use of pharmaceutical opioids among young polydrug users in Ohio. Addict Behav. (2009) 34:64953. doi: 10.1016/j.addbeh.2009.03.037

72. Kariisa M, Scholl L, Wilson N, Seth P, Hoots B. Drug overdose deaths involving cocaine and psychostimulants with abuse potentialUnited States, 2003-2017. MMWR Morb Mortal Wkly Rep. (2019) 68:388-95. doi: $10.15585 / \mathrm{mmwr} . \mathrm{mm} 6817 \mathrm{a} 3$
73. O’Donnell J, Gladden RM, Mattson CL, Hunter CT, Davis NL. Vital signs: characteristics of drug overdose deaths involving opioids and stimulants-24 states and the District of Columbia, January-June 2019. MMWR Morb Mortal Wkly Rep. (2020) 69:1189-97. doi: 10.15585/mmwr.mm6935al

74. DeSantis AD, Webb EM, Noar SM. Illicit use of prescription ADHD medications on a college campus: a multimethodological approach. J Am Coll Health. (2008) 57:315-24. doi: 10.3200/JACH.57.3.315-324

75. Faraone SV, Hess J, Wilens T. Prevalence and consequences of the nonmedical use of amphetamine among persons calling poison control centers. J Atten Disord. (2019) 23:1219-28. doi: 10.1177/1087054719843182

76. McCaffrey S, Manser KA, Trudeau KJ, Niebler G, Brown C, Zarycranski D, et al. The natural history of prescription opioid abuse: a pilot study exploring change in routes of administration and motivation for changes. $J$ Opioid Manag. (2018) 14:397-405. doi: 10.5055/jom.2018.0472

77. McCabe SE, West BT, Morales M, Cranford JA, Boyd CJ. Does early onset of non-medical use of prescription drugs predict subsequent prescription drug abuse and dependence? Results from a national study. Addiction. (2007) 102:1920-30. doi: 10.1111/j.1360-0443.2007.02015.x

78. McCabe SE, West BT. Medical and nonmedical use of prescription stimulants: results from a national multicohort study. J Am Acad Child Adolesc Psychiatry. (2013) 52:1272-80. doi: 10.1016/j.jaac.2013.09.005

79. Surratt HL, Kurtz SP, Buttram M, Levi-Minzi MA, Pagano ME, Cicero TJ. Heroin use onset among nonmedical prescription opioid users in the club scene. Drug Alcohol Depend. (2017) 179:131-8. doi: 10.1016/j.drugalcdep.2017.06.034

80. Tardelli VS, Bisaga A, Arcadepani FB, Gerra G, Levin FR, Fidalgo TM. Prescription psychostimulants for the treatment of stimulant use disorder: a systematic review and meta-analysis. Psychopharmacology (Berl). (2020) 237:2233-55. doi: 10.1007/s00213-020-05563-3

81. Barthel M, Stocking G, Holcomb J, Mitchell A. Nearly Eight-in-Ten Reddit Users Get News on the Site. (2016). Retrieved from: https://www.journalism. org/2016/02/25/reddit-news-users-more-likely-to-be-male-young-anddigital-in-their-news-preferences/

82. Adams N, Artigiani EE, Wish ED. Choosing your platform for social media drug research and improving your keyword filter list. J Drug Issues. (2020) 48. doi: $10.1177 / 0022042619833911$

83. Cavazos-Rehg P, Grucza R, Krauss MJ, Smarsh A, Anako N, Kasson E, et al. Utilizing social media to explore overdose and HIV/HCV risk behaviors among current opioid misusers. Drug Alcohol Depend. (2019) 205:107690. doi: $10.1016 /$ j.drugalcdep.2019.107690

84. D’Agostino AR, Optican AR, Sowles SJ, Krauss MJ, Escobar Lee K, CavazosRehg PA. Social networking online to recover from opioid use disorder: a study of community interactions. Drug Alcohol Depend. (2017) 181:5-10. doi: 10.1016/j.drugalcdep.2017.09.010

85. Foufi V, Timakum T, Gaudet-Blavignac C, Lovis C, Song M. Mining of textual health information from reddit: analysis of chronic diseases with extracted entities and their relations. J Med Internet Res. (2019) 21:e12876. doi: $10.2196 / 12876$

86. Meacham MC, Paul MJ, Ramo DE. Understanding emerging forms of cannabis use through an online cannabis community: an analysis of relative post volume and subjective highness ratings. Drug Alcohol Depend. (2018) 188:364-9. doi: 10.1016/j.drugalcdep.2018.03.041

87. Shatz I. Fast, free, and targeted: reddit as a source for recruting participants online. Soc Sci Comput Rev. (2017) 35:537-49. doi: $10.1177 / 0894439316650163$

88. MacDonnell K, Cowen E, Cunningham DJ, Ritterband L, Ingersoll K. Online recruitment of a non-help-seeking sample for an internet intervention: lessons learned in an alcohol-exposed pregnancy risk reduction study. Internet Interv. (2019) 17:100240. doi: 10.1016/j.invent.2019.100240

89. Johnson RB, Onwuegbuzie AJ. Mixed methods research: a research paradigm whose time has come. Educ Res. (2004) 33:14-27. doi: 10.3102/0013189X033007014

90. Ochieng BM, Meetoo D. Using mixed methods when researching communities. Nurse Res. (2015) 23:16-9. doi: 10.7748/nr.23.1.16.e1323

91. Vrecko S. Everyday drug diversions: a qualitative study of the illicit exchange and non-medical use of prescription stimulants on a university campus. Soc Sci Med. (2015) 131:297-304. doi: 10.1016/j.socscimed.2014. 10.016 
92. Plano Clark VL, Ivankova NV. Mixed Methods Research: A Guide to the Field. Thousand Oaks, CA: Sage Publications, Inc. (2017).

93. Wu YP, Deatrick JA, McQuaid EL, Thompson D. A primer on mixed methods for pediatric researchers. $J$ Pediatr Psychol. (2019) 44:905-13. doi: 10.1093/jpepsy/ jsz052

Conflict of Interest: RR and JG are employees of Inflexxion, an IBH Company. $\mathrm{SV}$ is an independent scientific writer who contracts with Inflexxion. Inflexxion contracts with FDA and multiple companies with interests in some of the products included in the compounds evaluated for this article. Although the sponsor was involved in reviewing the content of this article, all data collection, analysis, and ultimate data interpretation were made by the authors without sponsor influence. KA serves as an Advisor to Arbor Pharmaceutical Company and receives research funding from Takeda Pharmaceutical Company. In the past year, SF received income, potential income, travel expenses continuing education support, and/or research support from Takeda, OnDosis, Tris, Otsuka, Arbor, Ironshore, Rhodes, Akili Interactive Labs, Sunovion, Supernus, and Genomind. With his institution, he has US patent US20130217707 A1 for the use of sodium-hydrogen exchange inhibitors in the treatment of ADHD, receives royalties from books published by Guilford Press: Straight Talk about Your Child's Mental Health, Oxford University Press: Schizophrenia: The Facts and Elsevier: ADHD: Non-Pharmacologic Interventions, and also Program Director of www.adhdinadults.com.

Copyright () 2021 Vosburg, Robbins, Antshel, Faraone and Green. This is an openaccess article distributed under the terms of the Creative Commons Attribution License (CC BY). The use, distribution or reproduction in other forums is permitted, provided the original author(s) and the copyright owner(s) are credited and that the original publication in this journal is cited, in accordance with accepted academic practice. No use, distribution or reproduction is permitted which does not comply with these terms. 